\title{
A e-Saúde (eHealth) no contexto da presente emergência pandémica - a proteção de dados pessoais e a interoperabilidade nas aplicações móveis de rastreabilidade de contactos (tópicas reflexões)
}

https://doi.org/10.21814/uminho.ed.25.12

\section{Joana Covelo de Abreu}

Joana Covelo de Abreu (ORCID: 0000-0002-1850-6400) é Professora da Escola de Direito da Universidade do Minho e da Universidade Portucalense Infante D. Henrique. É investigadora do JusGov - Centro de Investigação em Justiça e Governação da Universidade do Minho, integrando o seu Conselho Executivo. É especialista designada pela Comissão Europeia - DG Justiça e Consumidores, para a modernização da cooperação judiciária em matéria civil. 


\section{CONSIDERAÇÕES PRELIMINARES SOBRE AIDEIADE "EMERGÊNCIA"}

Para a redação do presente contributo, a autora colocará a tónica na expressão “emergência” por a mesma ser capaz de encerrar em si dois sentidos ou significados que, atento o tópico e a reflexão visados, lhe parecem apropriados.

Se, por um lado, "emergência" visa significar um evento ou situação que, pela sua gravidade, demanda uma atuação expedita, de forma a dar uma resposta em conformidade, por outro lado, num sentido literal, "emergência" resulta "do ato de emergir", ou seja, de se sublevar relativamente a uma situação antecedente menos auspiciosa.

Ora, são estes dois sentidos que motivam a reflexão que se conduz tendo por referência que o seu pano de fundo será a proteção dos dados pessoais na União Europeia ante a promoção de soluções interoperáveis no domínio da e-Saúde (ou eHealth), escrutinando as soluções associadas às aplicações móveis em matéria de rastreabilidade de contactos no âmbito da pandemia.

Assim, se a crise pandémica global configura e encerra em si o primeiro sentido da palavra "emergência” - porque é 'O' evento que, pela sua gravidade, demanda uma atuação expedita - tentaremos, ao longo do texto, equacionar o seu impacto no domínio da saúde e os desenvolvimentos que têm sido realizados em termos e-Saúde (Saúde em linha), particularmente vocacionados à interoperabilidade de ferramentas digitais e, em termos concretizados, se as posiçôes institucionais perante as aplicações móveis de rastreio de contactos, visando o combate da COVID-19, poderão encerrar em si respostas suficientemente adequadas e necessárias em contexto de pandemia. Ora, e aqui reside o segundo sentido da expressão "emergência” - a busca pela resposta à seguinte pergunta: "será que as soluções digitais e tecnológicas que a União Europeia tem vindo a desenvolver dinamicamente no domínio da e-Saúde poderão ter um papel relevante a desempenhar neste contexto?”.

\footnotetext{
1 As considerações preliminares relativas à concetualização instrumental da expressão "emergência" correspondem, no essencial, à introdução da sua intervenção no Ciclo de Palestras, coordenado pelo Ex.mo Sr. Prof. Doutor Joaquim Freitas da Rocha, subordinado ao tema "Crise pandémica, estado de emergência e (algumas) respostas dos poderes públicos", que ocorreu no dia 11 de maio de 2020.

2 Cfr. Dicionário da Língua Portuguesa - Dicionários Académicos, Porto Editora, 1993, p. 270.
} 


\section{A E-SAÚDE NA UNIÃO EUROPEIA E O PAPEL DA INTEROPERABILI- DADE ADMINISTRATIVA}

Posto isto, no âmbito da Administração Pública em linha, outros têm sido os interesses públicos secundários a que se tem dado particular atenção enquanto objetivos que, em termos jurídico-administrativos, cabe à Administração Pública concretizar, implementar e regular ${ }^{3}$. Num contexto pandémico, parece-nos apropriado abordar a e-Saúde (ou Saúde em linha) no contexto amplo do Mercado Único Digital, a fim de intuir o quadro de políticas públicas que the subjaz e que considerações jurídicas merecerão equação, sobretudo tendo por referência o elevado padrão de proteção de dados pessoais vigente na União Europeia.

Sobre a matéria, a Comissão Europeia começou por adiantar, já em 2018, a necessidade de reformular "significativamente os [...] sistemas de saúde e de prestação de cuidados" a fim de garantir "que os mesmos se mantêm adequados à sua finalidade", ou seja, para que tais sistemas possam "continuar a promover a saúde, a prevenir doenças e a prestar cuidados centrados no doente", "requerem reformas e soluções inovadoras para se tornarem mais resilientes, acessíveis e eficazes na prestação de cuidados de qualidade aos cidadãos europeus”‘ .

Afinal, problemas como "o envelhecimento, a multimorbilidade, a escassez de recursos humanos no setor da saúde e o fardo cada vez maior representado pelas doenças não transmissíveis evitáveis, causadas por fatores de risco como o tabaco, o álcool e a obesidade, assim como outras doenças, incluindo as doenças neurodegenerativas e raras", a que se associa "uma ameaça crescente das doenças infeciosas devido a uma maior resistência aos antibióticos ou a agentes patogénicos novos ou recrudescentes” e, ainda, o aumento da despesa pública associada ao setor da "saúde e [d]os cuidados de

3 Cfr., para maior desenvolvimento, Freitas do Amaral, D. (2015), Curso de Direito Administrativo (Vol. I, 4a Edição). Coimbra: Almedina. pp. 87-114; e Fonseca, I. C. M. (2012). Direito da Organização Administrativa - Roteiro Prático. Coimbra: Almedina, pp. 21-23.

4 Cfr. Comissão Europeia (2018). Comunicação ao Parlamento Europeu, ao Conselho, ao Comité Económico e Social Europeu e ao Comité das Regiôes sobre a viabilização da transformação digital dos serviços de saúde e de prestação de cuidados no Mercado Único Digital, a capacitação dos cidadãos e a construção de uma sociedade mais saudável. COM(2018) 233 final. Bruxelas: 25 de abril de 2018, p. 1. 
longa duração" determinaram a necessidade de equacionar políticas públicas tendentes a uma alteração do fundamento e da própria teleologia que está na base dos sistemas de saúde e da prestação de cuidados ainda verificados na União Europeia 5 .

Para o efeito, "[a]s soluçóes digitais destinadas à saúde e aos cuidados podem [...] mudar radicalmente a forma como os serviços de saúde e cuidados são prestados aos doentes, se forem concebidas propositadamente e implementadas de uma forma eficaz em termos de custos" 6 , podendo diligenciar por melhores cuidados transfronteiriços, o que assume particular relevância num espaço integrado, como é o da União Europeia, onde se afirmam as liberdades de circulação e, especialmente, a livre circulação de pessoas.

Neste diapasão, verificou-se ainda que "[a] digitalização pode [...] ajudar a promover a saúde e a prevenir doenças [...]" e "[p]ode apoiar a reforma dos sistemas de saúde e a sua transiçã̃o para novos modelos de prestação de cuidados, centrados nas necessidades das pessoas e possibilitar a transição de sistemas centrados nos hospitais para estruturas de prestação de cuidados mais integradas e vocacionadas para a comunidade" . Nesta perspetiva, as ferramentas digitais ao serviço da saúde têm a capacidade de deslocalizar a tónica da cura para a prevenção da doença, podendo "converter os conhecimentos científicos num meio para ajudar os cidadãos a manterem-se saudáveis, ajudando, assim, a assegurar que não adoeçam”.

No entanto, para que estas incursões possam ser bem-sucedidas, assentam na existência de dados - mormente, pessoais e de caráter especialmente sensível, como teremos oportunidade de analisar infra - já que estes "constituem um fator essencial para a transformação digital"', verificando-se discrepâncias significativas entre os Estados-Membros na forma como tratam tais dados e como os colocam ao serviço e à disposição da investigação científica, das autoridades públicas e dos profissionais de saúde. Ora, só com uma utilização otimizada desses dados (e da "disponibilidade de grandes

5 Idem, p. 1.

6 Ibidem, p. 1.

7 Ibidem, p. 1.

8 Ibidem, pp. 1 e 2.

9 Ibidem, p. 2. 
quantidades de dados de elevada qualidade"10) e através de bases de dados e de soluções interoperáveis entre sistemas de saúde é que se poderá almejar uma "abordagem integrada que garanta [...] a prevenção de doenças" e que "os cuidados de saúde e os tratamentos respondam melhor às necessidade das pessoas" ${ }^{\prime 1}$.

Assim, desde que a União Europeia apostou no estabelecimento de um Mercado Único Digital, reconheceu a importância de equacionar a potencialização digital dos serviços de saúde: já em 2015, a Comissão Europeia se comprometia a lançar "um plano integrado de normalização a fim de identificar e definir prioridades-chave de normalização, com especial destaque para as tecnologias e domínios que são considerados de importância crítica para o Mercado Único Digital, incluindo normas e interoperabilidade setoriais essenciais em domínios como a saúde (telemedicina, saúde móvel)”12.

Para além de sublinhar a dinâmica digital que visava imprimir, também, desde cedo, reputou essencial promover a interoperabilidade das bases de dados e dos sistemas de saúde, na medida em que se afigurava como a medida menos dispendiosa de integrar, à escala europeia, grandes quantidades de dados, através de esforços que poderão ser suscetíveis de se compatibilizar com a proteção de dados pessoais. Afinal, nos termos do artigo 2o, № 1 da Decisão oo 2015/2240 ${ }^{13}$ - que estabelece o Programa ISA ${ }^{2}$ - interoperabilidade significa "a capacidade de organizaçốes díspares e diversas interagirem com vista à consecução de objetivos comuns com benefícios mútuos, definidos de comum acordo, implicando a partilha de informações e conhecimentos entre si, no âmbito de processos administrativos a que dão apoio, mediante o intercâmbio de dados entre os respetivos sistemas de TIC”.

10 Ibidem, p. 2.

11 Ibidem, p. 2.

12 Cfr. Comissão Europeia (2015). Comunicação ao Parlamento Europeu, ao Conselho, ao Comité Económico e Social Europeu e ao Comité das Regioões - Estratégia para o Mercado Único Digital na Europa. $\operatorname{COM}(2015) 192$ final. Bruxelas: 6 de maio de 2015, p. 18.

13 Cfr. Decisão (UE) no 2015/2240, do Parlamento Europeu e do Conselho, de 25 de novembro, que cria um programa sobre soluções de interoperabilidade e quadros comuns para as administraçóes públicas, as empresas e os cidadãos europeus (Programa ISA2) como um meio para modernizar o setor público. 
No mesmo sentido, na revisão intercalar da estratégia para o Mercado Único Digital, a Comissão avançava a importância de uma economia dos dados no domínio da saúde e dos cuidados de saúde, entendendo que "[a]s tecnologias digitais podem contribuir para melhorar a saúde das pessoas e resolver problemas sistémicos dos sistemas de saúde", proporcionando "instrumentos economicamente eficientes" mas “desenvolvidos no pleno respeito das regras de proteção de dados"14. Nesta mesma revisão intercalar, adiantava-se ainda que “[a] Comissão est[ava] a trabalhar com os Estados-Membros para assegurar que os cidadãos pod[ia] $m$ transferir os seus registos de saúde eletrónicos por via eletrónica quando recebe[sse]m tratamento médico noutro Estado-Membro e utiliza[sse]m receitas eletrónicas para obter os medicamentos prescritos", sistema este previsto para estar operacional no ano de "2020 na maioria dos Estados-Membros”15.

Assim, desenhava-se claramente, no contexto europeu, a sensibilidade de que o caminho para uma e-Saúde se trilharia a partir da interoperabilidade ${ }^{16}$ - como, aliás, também parecia resultar da Diretiva 2011/24/UE ${ }^{17}$. Nos termos do artigo 14oㅡ, nos 1 e 2, a) da mencionada Diretiva, a União Europeia promove e apoia a cooperação e o intercâmbio de informações científicas entre os Estados-Membros no âmbito de uma rede voluntária composta pelas autoridades responsáveis pela e-Saúde, designadas pelos Estados-Membros, visando, com tal rede, a criação de sistemas e serviços de saúde em linha e de aplicações interoperáveis.

14 Cfr. Comissão Europeia (2017). Comunicação ao Parlamento Europeu, ao Conselho, ao Comité Económico e Social Europeu e ao Comité das Regiões sobre a revisão intercalar relativa à aplicação da Estratégia para o Mercado Único Digital - Um Mercado Único Digital conectado para todos. COM(2017) 228 final, Bruxelas: 10 de maio de 2017, pp. 21 e 22.

15 Idem, p. 22.

16 Cfr, para maiores desenvolvimentos, Covelo de Abreu, J. (2019). Os serviços digitais na União Europeia: a interoperabilidade administrativa e a e-Saúde (eHealth), in Carvalho, M. M., E.Tec Yearbook - Health and Technology (pp. 53-68). Braga: JusGov - Research Centre for Justice and Governance, School of Law - University of Minho, disponível em https://issuu.com/comunicadireito/docs/etec_yearbook_n2 [acesso: 24.6.2020]. 17 Cfr. Diretiva (UE) no 2011/24/UE, do Parlamento Europeu e do Conselho, de 9 de março de 2011, relativa ao exercício dos direitos dos doentes em matéria de cuidados de saúde transfronteiriços. 
Por sua vez, e já em julho de 2019, foi publicada uma brochura informativa onde se encontram explanados os objetivos de investigação e de inovação, associados às novas tecnologias de informação, e como estes se encontram ao serviço da saúde ${ }^{18}$. Para o efeito, este documento institucional apresentava os diversos projetos financiados, a nível europeu, em matéria de interoperabilidade administrativa no domínio da e-Saúde, nomeadamente "[p]rojetos que inovam o sistema de saúde e de prestação de cuidados de saúde e a forma como este funciona", incluindo "projetos que se relacionam com a interoperabilidade - significando a capacidade de sistemas e organizações trabalharem em conjunto (interoperarem)" 19 .

Surgem, assim, projetos especificamente vocacionados à interoperabilidade na área da saúde, como o PHArA-ON - que cria "um conjunto de plataformas abertas interoperáveis integradas e elevadamente customizadas" para impactar na população europeia envelhecida ${ }^{20}$; o Smart4Health - que cria um sistema de intercâmbio de registos médicos eletrónicos, centrado no cidadão, para estimular cuidados de saúde personalizados ${ }^{21}$; o InteropEHRate - que visa promover a interoperabilidade dos registos médicos eletrónicos, mediada pelo paciente, e que, perante a sua autorização, poderá acarretar uma interoperabilidade transfronteiriça entre os registos médicos e as aplicações de investigação científica 22; o ASSESS CT - que tem em vista "contribuir para uma melhor interoperabilidade semântica nos serviços de e-Saúde na Europa ${ }^{23 " ;}$ o $e$-Standards - que "avança uma interoperabilidade na e-Saúde e um alinhamento global dos padrões”, através do envolvimento das partes interessadas, responsáveis pela partilha de boas práticas e de conhecimentos e que permitirá a definição de padróes

18 Cfr. Comissão Europeia (2019). Research and innovation in the field of ICT for health, wellbeing and ageing: an overview. Bruxelas: Directorate-General for Communications Networks, Content and Technology - Digital Society, Trust and Cybersecurity, disponível em https://ec.europa.eu/information society/newsroom/image/document/2019-33/health_ageing_projects_list_2019_6BC92EFF-90F3-8A94-09FBFA3C4DFD150E_61321.pdf [acesso: 25.6.2020].

19 Idem, p. 3 (tradução livre).

20 Ibidem, p. 41 (tradução livre).

21 Ibidem, p. 41.

22 Ibidem, p. 41.

23 Ibidem, p. 42 (tradução livre). 
comuns $^{24}$; o EURO-CAS - que visa testar as soluçóes interoperáveis em matéria de e-Saúde já implementadas e adequá-las ao quadro aplicável em matéria de interoperabilidade vigente na União Europeia ${ }^{25}$; o openMedicine - que visa promover um sistema de saúde transfronteiriço melhor e mais seguro através de um sistema interoperável de prescriçôes médicas eletrónicas/digitais ${ }^{26}$; e o VALUeHEALTH - que visa "estabelecer como a interoperabilidade na e-Saúde pode criar e apresentar valor para todos os cidadãos, para um mercado sustentável de serviços transfronteiriços”27.

Há, ainda, outros projetos que, apesar de não terem, como referência primordial, o estabelecimento de uma interoperabilidade no domínio da e-Saúde, acabam por utilizar este método para atingir os seus resultados, como é o caso do HeartMan - que cria um "sistema de saúde pessoal para ajudar pacientes com insuficiência cardíaca congestiva a lidar com a sua condiçãa” visando ainda estabelecer "um sistema de gestão de dados padronizado para ampla interoperabilidade"28; do UNWIRED Health - que cria um sistema de saúde móvel (mHealth) na área da insuficiência cardíaca, através de uma aplicação, e que envolve associaçốes sem fins lucrativos para "promover o desenvolvimento de plataformas abertas e soluçóes interoperáveis" ${ }^{29}$; ou do THALEA छे THALEA II - que, através do envolvimento de cinco hospitais da Alemanha, Holanda, Espanha, Bélgica e Finlândia, se "focaliza em ter uma plataforma interoperável de telemedicina e de telemonitorização [...] para melhorar o desempenho em pacientes em risco de vida das unidades de cuidados intensivos"30.

Posto isto, compreende-se a importância das plataformas interoperáveis pois "têm a virtualidade de promover melhores serviços públicos e de esbater as discrepâncias de tratamento desses serviços entre Estados-Membros, numa perspetiva de maior integração via a dimensão digital e de entrosamento do cidadão (administrado = paciente) no

24 Ibidem, p. 42 (tradução livre).

25 Ibidem, pp. 42 e 43.

26 Ibidem, p. 43.

27 Ibidem, p. 44 (tradução livre).

28 Ibidem, p. 16 (tradução livre).

29 Ibidem, p. 17 (tradução livre).

30 Ibidem, p. 39 (tradução livre). 
procedimento a que está sujeito ou em que é visado"31. No entanto, para que tal caminho possa ser determinado, há a necessidade de equacionar o seu impacto e os seus riscos, de forma a que as soluçóes encontradas não se revelem perigosas para os pacientes, pela manipulação de dados pessoais de natureza especial sem observar o padrão protetivo em vigência na União Europeia.

A propósito, o próximo capítulo explica o impacto da interoperabilidade na proteção de dados e os regimes jurídicos equacionáveis e analisa a recente produção institucional europeia e nacional quanto às aplicaçôes de rastreabilidade de contactos no combate à COVID-19.

\section{A PROTEÇÃO DE DADOS PESSOAIS E A INTEROPERABILIDADE ADMINISTRATIVA - BREVES REFLEXÕES A PROPÓSITO DAS APLI- CAÇÕES MÓVEIS INTEROPERÁVEIS DE RASTREABILIDADE DE CONTACTOS NO ÂMBITO DA PANDEMIA}

A interoperabilidade pressupóe, deste modo, a articulação entre sistemas digitais e bases de dados, geridos por entes na área da saúde e da investigação científica (públicos e privados), a fim de promover uma acessibilidade aos dados de saúde para fomentar uma alteração do padrão atualmente vigente: passando a apostar na prevenção e não tanto na cura da doença. Para que os dados sejam atualizados, os projetos analisados pressupóem também - e a tendência política também é reveladora dessa dinâmica - o entrosamento dos cidadãos (pacientes) que, presumindo-se devidamente cientes dos dados que estão a facultar, possam, numa perspetiva de proximidade e atualidade, introduzir os seus dados pessoais em matéria de saúde. No entanto, para que as ferramentas digitais possam funcionar, há ainda a necessidade de equacionar os acessos detidos por entes que procedem à dinamização e/ou atualização tecnológica daquelas ferramentas.

Se esta articulação de prestadores de cuidados de saúde, investigadores, pacientes e agentes ligados à área tecnológica já levanta algumas preocupações, em matéria de

31 Cfr. Covelo de Abreu, J. (2019). Os serviços digitais na União Europeia: a interoperabilidade administrativa e a e-Saúde (eHealth)..., p. 63. 
proteção de dados pessoais, cabe ainda sublinhar que as soluçôes interoperáveis a serem pensadas, no contexto da União Europeia, pressupóem registos, plataformas e bases de dados transfronteiras, só assim se compaginando com as liberdades de circulação que pautam este espaço e com a necessidade de alinhamento da prestação de cuidados de saúde por um padrão elevado em todos os Estados-Membros. Assim, neste contexto, a interoperabilidade demanda também a interconexão daquelas ferramentas com os sistemas comparáveis implementados (ou a implementar) nas instituições, órgãos e organismos da União, nomeadamente perante o Centro Europeu de Prevenção e Controlo das Doenças $(\mathrm{ECDC})^{32}$, podendo inclusivamente caber a uma destas estruturas orgânicas europeias a gestão transfronteiriça desses instrumentos interoperáveis.

Assim, os dados tratados de forma interoperável encontram-se sujeitos ao atual padrão jus fundamental da União Europeia em matéria de proteção de dados pessoais ${ }^{33}$ que resulta concretizado em dois atos normativos europeus - no Regulamento Geral sobre a Proteção de Dados (RGPD) ${ }^{34}$ e no Regulamento no 2018/1725 $5^{35}$ e ${ }^{36}$. Afinal, o RGPD é aplicável a todas as entidades públicas e privadas que tratam dados pessoais com finalidades não domésticas enquanto o segundo é aplicável ao tratamento de dados pessoais realizado por instituições, órgãos e organismos da União Europeia.

32 Cfr., para maiores desenvolvimentos, Covelo de Abreu, J. (no prelo). Centro Europeu de Prevenção e Controlo das Doenças (ECDC). In Covelo de Abreu, J. e Reis, L. (Coords.). Instituiçôes, órgãos e organismos da União Europeia: um quadro institucional unico?

33 Cfr., a propósito, artigos 16 do Tratado sobre o Funcionamento da União Europeia (TFUE) e 8o da Carta dos Direitos Fundamentais da União Europeia (CDFUE).

34 Cfr. Regulamento (UE) № 2016/679, do Parlamento Europeu e do Conselho, de 27 de abril, relativo à proteção das pessoas singulares no que diz respeito ao tratamento de dados pessoais e à livre circulação desses dados e que revoga a Diretiva 95/46/CE (Regulamento Geral sobre a Proteção de Dados).

35 Cfr. Regulamento (UE) no 2018/1725, do Parlamento Europeu e do Conselho, de 23 de outubro de 2018, relativo à proteção das pessoas singulares no que diz respeito ao tratamento de dados pessoais pelas instituiçốes e pelos órgãos e organismos da União e à livre circulação desses dados, e que revoga o Regulamento (CE) no 45/2001 e a Decisão no 1247/2002/CE.

36 Cfr., para maiores desenvolvimentos, Covelo de Abreu, J. (2019). O Mercado Único Digital e a interoperabilidade administrativa: a proteção de dados pessoais na articulação entre administrações públicas nacionais e as instituições e órgãos da União Europeia - reflexões prospectivas. In Amado Gomes, C., Neves, A. F., Bitencourt Neto, F. e Motta, F. (Coords.). O Direito Administrativo nos 30 anos da Constituição Brasileira de 1988 - Um diálogo luso-brasileiro. (pp. 206-242). Lisboa: ICJP / CIDP. Disponível em https://www.icjp.pt/sites/ default/files/publicacoes/files/ebook da30anoscb icjp15mar2019.pdf [acesso: 30.6.2020]. 
Posto isto, os dados pessoais recolhidos, disponibilizados e manipulados no âmbito de plataformas digitais interoperáveis, encontram-se sujeitos à aplicação daqueles dois normativos, na medida em que, neste contexto, o tratamento de dados pessoais se reputa como "uma operação ou um conjunto de operaçóes efetuadas sobre dados pessoais ou sobre conjuntos de dados pessoais, por meios automatizados ou não automatizados, tais como a recolha, o registo, a organização, a estruturação, a conservação, a adaptação ou alteração, a recuperação, a consulta, a utilização, a divulgação por transmissão, difusão ou qualquer outra forma de disponibilização, a comparação ou interconexão, a limitação, o apagamento ou a destruição" (ênfase nosso), conforme se encontra disposto nos artigos 4o, no 2 do RGPD e 3o, no 3 do Regulamento no 2018/1725.

Ora, deste modo, os dados em causa poderão ter um regime protetivo especial por se tratarem de dados pessoais relativos à saúde da pessoa singular em causa. Afinal, conforme resulta dos artigos 9ㅇ, no 1 do RGPD e 10으, o 1 do Regulamento no 2018/1725, é, em regra, proibido o tratamento de categorias especiais de dados pessoais, concretamente de "dados relativos à saúde" da pessoa singular, apenas sendo lícita a condução de tal tratamento se se subsumir a uma das causas de licitude de tratamento constantes nos artigos 9, ํo 2 do RGPD e 10o, no 2 do Regulamento № 2018/1725.

Assim, num contexto como o que estamos a explorar - da implementação de soluções interoperáveis, com particular relevância perante a pandemia associada ao Coronavírus -, será possível (e lícito) o tratamento de dados sensíveis quando i) o titular dos dados tiver dado o seu consentimento explícito; ii) o tratamento for necessário por motivos de interesse público importante, com base no direito da União, devendo ser proporcional ao objetivo visado e respeitando a essência do direito à proteção de dados e demais direitos fundamentais e interesses do titular dos dados; e iii) o tratamento for necessário por motivos de interesse público no domínio da saúde pública, nos termos dos artigos 9o, no 2, a), g) e i) do RGPD e 10oㅡ믄 2, a), g) e i) do Regulamento no 2018/1725).

Posto isto, e tendo em conta o papel de particular relevância da adesão dos particulares a este tipo de ferramentas, "há a necessidade de promover uma sensibilização para a literacia digital no domínio da e-Saúde para que os pacientes, cada vez mais 
entrosados, tenham a verdadeira noção das vantagens de um sistema interoperável (quer em termos de telemedicina, quer em termos de prescrição digital, de registo médico digital e demais realidades que poderão divisar-se no futuro) e os riscos que o mesmo acarreta, devendo ainda estar cientes dos direitos que os assistem em termos de proteção de dados e, bem assim, as circunstâncias em que os mesmos podem ser reivindicados administrativa e/ou judicialmente, quer à luz do RGPD, quer à luz do Regulamento no 2018/1725”37.

Daqui parece resultar que as soluções legislativas adotadas em sede de proteção de dados estão abstratamente adequadas a enquadrar, sob o ponto de vista regulatório, estes desenvolvimentos interoperáveis em sede de e-Saúde. Por sua vez, e atendendo à necessidade de entrosamento das pessoas singulares (pacientes) nestas dinâmicas, os compromissos assumidos, pela Comissão Europeia, em sede de literacia digital, parecem alinhar-se com a consequente observância do padrão de proteção de dados pessoais vigente na União Europeia. Afinal, a Comissão comprometeu-se a promover ações de capacitação digital, na área da saúde, "dos cidadãos, doentes e profissionais do setor da saúde” em articulação com “organizações profissionais de saúde e universidades”38.

Afinal, a aposta nas ferramentas digitais ao serviço de uma e-Saúde tem em vista "promover uma maior participação dos cidadãos para que os sistemas de saúde possam, gradativamente, alterar o seu objetivo do tratamento de doenças para a promoção da prevenção" 39 já que, numa perspetiva antropocêntrica, a Comissão reconheceu que "os sistemas de saúde necessitam de transitar do tratamento para a promoção da saúde e a prevenção de doenças, de uma concentração na doença para uma concentração no bem-estar das pessoas, e da fragmentação para a integração e coordenação dos serviços em todo o ciclo de cuidados", sublinhando, para o efeito, “a cooperação ativa entre

37 Cfr. Covelo de Abreu, J. (2019). Os serviços digitais na União Europeia: a interoperabilidade administrativa e a e-Saúde (eHealth)..., p. 64.

38 Cfr. Comissão Europeia (2018). A viabilização da transformação digital dos serviços de saúde e de prestação de cuidados no Mercado Único Digital..., p. 15.

39 Cfr. Covelo de Abreu, J. (2019). Os serviços digitais na Uniäo Europeia: a interoperabilidade administrativa e a e-Saúde (eHealth)..., p. 64. 
profissionais de saúde e doentes" pela "utilização de soluções digitais que proporcionam os meios necessários para prestar cuidados eficientes e eficazes em termos de custos”40.

Posto isto, quer as autoridades europeias, quer as autoridades nacionais têm estado atentas ao momento de pandemia que se atravessa, por conta da COVID-19, cabendo enunciar os desenvolvimentos que se têm verificado no domínio da e-Saúde. Assim, votaremos a nossa atenção às considerações feitas a propósito das aplicações móveis de rastreabilidade de contactos, analisando, para o efeito, o Relatório Técnico do ECDC, de 10 de junho de 2020, e equacionando a recente Deliberação da CNPD que decide sobre uma avaliação de impacto de uma aplicação que visa monitorizar a exposição ao risco de contágio da COVID-19 sobre a proteção de dados, datada de 29 de junho de 2020.

O ECDC adotou um Relatório Técnico intitulado "Aplicações móveis para a rastreabilidade de contactos no âmbito da COVID-19" onde sublinhou que "a rastreabilidade de contactos é de particular significância quando as medidas de confinamento são levantadas" já que "[a]s aplicações móveis (apps) podem ajudar a rastrear e a alertar mais contactos já que não se baseiam apenas na memória da pessoa infetada" e, inclusivamente, "podem também rastrear contactos desconhecidos para o caso", "notificar contactos rapidamente" e "podem facilitar a rastreabilidade transfronteiriça de contactos” ${ }^{\sharp 1}$. No entanto, reafirma a necessidade de estas aplicaçóes poderem apenas ter um papel instrumental complementar à rastreabilidade regular de contactos, desde logo porque nem todos têm acesso a um smartphone nem se pode impor a necessidade de instalação da aplicação, já que "[o] uso de aplicações móveis deve ser voluntário”, sobretudo porque se colocam, ao próprio ECDC, várias questóes em matéria de proteção de dados que têm de ser devidamente equacionadas ${ }^{42}$.

40 Cfr. Comissão Europeia (2018). A viabilização da transformação digital dos serviços de saúde e de prestą̧ão de cuidados no Mercado Único Digital..., p. 12.

41 Cfr. Centro Europeu de Prevenção e Controlo das Doenças - ECDC (2020). Technical Report - Mobile applications in support of contact tracing for COVID-19. A guidance for EU/EEA Member States. (junho de 2020) p. 1 (tradução livre). Disponível em https://www.ecdc.europa.eu/sites/default/files/documents/COVID-19-mobile-applications-contact-tracing.pdf [16.6.2020].

42 Idem, p. 1 (tradução livre). 
Tal como explicado pelo ECDC, estas aplicações móveis de rastreabilidade de contactos estão a ser desenvolvidas em vários Estados-Membros, normalmente baseadas na tecnologia Bluetooth, e visam identificar, ao utilizador da aplicação, que se encontrou, durante um período de tempo determinado (quinze minutos ou mais) ${ }^{43}$, em contacto com alguém que se mostrou infetado por Coronavírus. Para o efeito, a identidade da pessoa infetada não será revelada ao outro utilizador, havendo a necessidade de, aquando da passagem da informação, serem indicados a este último os meios de saúde pública a acionar. Para o efeito, o ECDC sublinhou a necessidade de tais aplicações não precisarem de se basear em sistemas de geolocalização e na colheita dos respetivos dados, devendo pautar-se pelo princípio da minimização dos dados recolhidos e da sua manutenção pelo período de tempo mínimo necessário à realização dos objetivos visados ${ }^{44} \mathrm{e} 45$.

Tal Relatório Técnico alinhou-se com a Comunicação da Comissão Europeia que estabeleceu orientaçóes respeitantes a aplicações móveis de apoio à luta contra a pandemia de COVID-19 na perspetiva da proteção de dados ${ }^{46}$, a fim de "garantir uma abordagem coerente em toda a UE e [de] fornecer orientações aos Estados-Membros e aos criadores de aplicações móveis", incidindo "apenas nas aplicações móveis de utilização voluntária para apoio na luta contra a pandemia da COVID-19 (aplicações descarregadas, instaladas e utilizadas voluntariamente pelos cidadãos)”, nomeadamente, aquelas que contam com funcionalidades de "rastreio de contactos e alerta" ou de "criação de um fórum de comunicação para médicos e pacientes em situação de autoisolamento e para os casos em que é prestado aconselhamento ulterior em matéria de diagnóstico e de tratamento (maior utilização da telemedicina) ${ }^{\$ 47}$.

43 Ibidem, p. 10.

44 Ibidem, pp. 2, 4 e 5.

45 Cfr., para maiores desenvolvimentos, eHealth Network (2020). Mobile Applications to support contact tracing in the EU's fight against COVID-19-Common EU Toolbox for Member States. Bruxelas. (Versão 1.0, 15 de abril de 2020). Disponível em https://ec.europa.eu/health/sites/health/files/ehealth/docs/COVID-19_apps_ en.pdf [acesso: 16.6.2020].

46 Cfr. Comissão Europeia (2020). Comunicação - Orientaçôes respeitantes a aplicaçôes móveis de apoio à luta contra a pandemia de COVID-19 na perspetiva da proteção de dados. Bruxelas:17 de abril de 2020. (2020/C 124I/01).

47 Idem, p. 2. 
Para o efeito, a Comissão sublinhou que, "[d]ada a sensibilidade dos dados em questão e a finalidade do tratamento de dados [...], as aplicações devem ser concebidas de modo a que os responsáveis pelo tratamento sejam as autoridades nacionais de saúde (ou entidades que desempenham funções de interesse público na área da saúde)”, às quais caberá "assegurar a conformidade com o RGPD (princípio da responsabilidade) ${ }^{348}$. Por outro lado, tais aplicações deverão garantir que são as pessoas que mantêm o controlo dos seus dados: desde logo, pelo caráter voluntário da instalação da aplicação (e a consequente possibilidade de desinstalação livre e desativação da aplicação quando a pandemia for declarada sob controlo), mas também pelo facto de não se promover um agrupamento das diferentes funcionalidades da aplicação, "de modo a permitir que as pessoas possam dar o seu consentimento separado para cada uma das funcionalidades" e de se assegurarem, neste contexto, todos os direitos, ao titular dos dados, reconhecidos pelo RGPD (artigos 15o e seguintes) ${ }^{49}$.

O elevado padrão de proteção de dados pessoais sai assegurado se os responsáveis pelo tratamento forem capazes de promover a minimização dos dados tratados ${ }^{50}$, a limitação na divulgação e no acesso aos dados $^{51}$, o estabelecimento das finalidades exatas do tratamento ${ }^{52} \mathrm{e}$ a fixação de limites estritos de conservação dos dados ${ }^{53}$.

Para o efeito, o papel das autoridades de proteção de dados sai reforçado, chamando a Comissão Europeia a atenção para o artigo 35o do RGPD, que estabelece o regime da avaliação de impacto sobre a proteção de dados ${ }^{54}$.

Ora, neste contexto, a CNPD foi chamada a pronunciar-se, em consulta prévia, quanto a uma avaliação de impacto sobre a proteção de dados de um sistema (STAYWAY COVID), para rastreio da propagação da COVID-19, através da utilização voluntária de

48 Ibidem, p. 3.

49 Ibidem, p. 4.

50 Ibidem, pp. 5 e seguintes.

51 Ibidem, p. 7.

52 Ibidem, p. 7.

53 Ibidem, p. 8.

54 Ibidem, p. 9. 
uma aplicação para dispositivos móveis pessoais, mediante pedido apresentado pelo Instituto de Engenharia de Sistemas e Computadores, Ciência e Tecnologia - INESC TEC 55 .

Assim, a CNPD concluiu que "[o] sistema deve preservar o seu caráter voluntário, devendo ser facultado ao utilizador, tal como previsto, vários momentos em que pode livremente fazer opções quanto ao tratamento dos seus dados, incluindo a possibilidade efetiva de desligar o Bluetooth, configurar a aplicação para não rastrear contactos de proximidade e desinstalar a aplicação, tendo como consequência a interrupção ou o apagamento definitivo dos seus dados" "56 pugnando, ainda, quanto ao regime da transparência (decorrente dos artigos 12o e seguintes do RGPD), que "os titulares dos dados devem estar sempre cientes de todos os aspetos do funcionamento da aplicação" já que "muitas interações ocorrem automaticamente, sem que o utilizador se aperceba delas" ${ }^{57}$.

Nesta sequência, a CNPD reputou a "utilização da tecnologia Bluetooth" como "menos intrusiva do que o recurso a uma tecnologia que permitisse de imediato registar a localização do utilizador”. No entanto, reforça que tal tecnologia não se encontra isenta de riscos, nomeadamente se se verificar a imprescindibilidade de manter o sistema ativo, circunstância em que "está a habilitar o rastreamento constante da localização e movimentações dos utilizadores por terceiros" ${ }^{\text {"58 }}$. Por sua vez, também entende como fragilidade do sistema o facto de ter de recorrer "à interface da Google e da Apple [...], na medida em que há uma parte crucial da sua execução que não é controlada pelos autores da aplicação ou pelos responsáveis pelo tratamento" 59 .

Por fim, a CNPD ainda deixou um alerta que se alinha às consideraçóes antecedentes realizadas na medida em que recordou que "[a] interoperabilidade entre as aplicaçôes nacionais de rastreamento de contactos de proximidade implica o tratamento de

55 Tal sistema resultava de uma iniciativa conjunta do INESC TEC e do Instituto de Saúde Pública da Universidade do Porto (ISPUP).

56 Cfr. Comissão Nacional de Proteção de Dados - CNPD (2020). Deliberação no 2020/277, de 29 de junho de 2020. Processo PRE/2020/6, parágrafo 86, pp. 10v e 11.

57 Idem, parágrafo 90, p. 11.

58 Ibidem, parágrafo 87, p. 11.

59 Ibidem, parágrafo 89, p. 11. 
mais dados, mais comunicações e mais destinatários, pelo que é preciso garantir que as opções tomadas nesse contexto respeitem os princípios da proteção de dados, em particular o princípio da minimização”, devendo os responsáveis pelo tratamento, inclusivamente "garantir que, com a interoperabilidade, as salvaguardas em matéria de proteção de dados não sucumbem a um mínimo denominador comum, mas antes procuram atingir um nível elevado de proteção da privacidade dos seus utilizadores" ${ }^{60}$.

Do exposto resulta uma coincidência da tomada de posição técnico-científica por parte do ECDC e da posição veiculada, perante um caso concreto, pela CNPD. No entanto, em qualquer um dos casos, ambas as entidades alertam para os riscos mais abrangentes decorrentes da utilização destas aplicações numa perspetiva interoperável, o que pede um dimensionamento diferente dos problemas inerentes à proteção dos dados pessoais.

\section{REFLEXÕES CONCLUSIVAS}

Ora, do que foi aqui explanado, a pandemia associada à COVID-19 parece ter despertado a promoção de finalidades que estavam ainda em fase de maturação na União Europeia, nomeadamente no âmbito da e-Saúde.

Na realidade, a nova Comissão Europeia, sob a batuta de Úrsula von der Leyen, publicava, em fevereiro de 2020, uma comunicação relativa ao futuro digital da Europa, onde adiantava que “[o] poder dos dados é essencial para o setor da saúde”, já que “[r]egistos de saúde digitais, reunidos num espaço europeu de dados de saúde, podem conduzir a um melhor tratamento de condições crónicas mais graves, incluindo cancro e doenças raras, mas também a um acesso igualitário a serviços de saúde de elevada qualidade a todos os cidadãos”, estimando, apenas a partir de 2022, como prioridade chave, “a promoção de registos eletrónicos de saúde baseados num formato comum europeu de interconexão a fim de assegurar aos cidadãos europeus um acesso seguro e para permitir a troca de dados de saúde pela UE” e a dotação de “um espaço europeu de dados de saúde para melhorar a

60 Ibidem, parágrafo 95, pp. 11v e 12. 
acessibilidade fiável e segura a dados de saúde para investigação, diagnóstico e tratamento focalizados e rápidos ${ }^{61}$.

Tal como aventámos, a "emergência” associada à pandemia pode também significar a capacidade de se sublevar em circunstâncias mais adversas, de se reinventar, de ser capaz de trazer para o presente ideias ou conceções que apenas estavam pensadas para o futuro.

Ora, no contexto da e-Saúde e, especificamente, quanto à utilização de ferramentas interoperáveis, verifica-se que se encontram a ser desenvolvidas e a ser escrutinadas, numa tentativa de conter a disseminação do Coronavírus, várias soluções que eram equacionadas enquanto projetos-piloto ou como atividades a votar atenção no futuro. Para o efeito, vários são os esforços de adoção de aplicações móveis para permitir a rastreabilidade de contactos a fim de evitar o contágio dos utilizadores ou de lhes criar uma noção dos contágios potenciais, determinando a sua mobilização ativa e a sua interação com as autoridades de saúde, em caso de referenciação de contactos suspeitos.

No entanto, para que tais aplicações prossigam as finalidades de saúde pública que lhes estão inerentes, têm de observar o elevado padrão de proteção de dados visado pela União Europeia, o que determinou que as autoridades europeias e nacionais - quer em matéria de saúde pública, quer em matéria de proteção de dados - tenham adotado uma posição concertada face aos desenvolvimentos destas ferramentas digitais, visando, simultaneamente, i) que as pessoas singulares cujos dados serão usados se encontrem numa posição de controlo dos mesmos, exercendo a sua adesão/não adesão voluntária a estes instrumentos, tal como o regime da proteção de dados lhes reconhece, ii) mas não ataviando a inovação científica, tecnológica e de valor acrescentado para as áreas da saúde pública e da economia, antes optando por uma veia didática e de constante acompanhamento e atualização.

Por sua vez, tais iniciativas não podem obliterar um dos desígnios fundamentais em matéria de e-Saúde pois, atento o facto de envolver o tratamento de dados

61 Cfr. Comissão Europeia (2020). Shaping Europe's Digital Future. Bruxelas: Publications Office of the European Union (fevereiro de 2020). p. 6. 
pessoais de caráter sensível, com a possibilidade de implicar um tratamento transfronteiriço interoperável, é importante apostar na literacia digital de todos os que contactarão com tais aplicações:

- Desde logo, os particulares, enquanto titulares dos dados, pois só assim estes têm o efetivo controlo sobre a aplicação e a sua caracterização como voluntária é assegurada em toda a sua plenitude;

- Também os profissionais de saúde e os investigadores que tenham acesso a tais dados, na medida em que terão de se consciencializar que, nessa perspetiva, tratam dados pessoais (sendo a maioria de caráter especial) e que, como tal, os mesmos apenas se poderão vocacionar às finalidades para que foram recolhidos, dentro das áreas de atuação de cada classe;

- Por outro lado, as entidades públicas/privadas que atuam enquanto responsáveis pelo tratamento/subcontratantes, às quais cabe promover a observância do princípio da minimização dos dados e a obrigação de dar cumprimento escrupuloso ao regime da transparência, no momento da recolha dos dados pessoais, prestando as informaçôes constantes nos artigos 12o e seguintes do RGPD.

Tempos desafiantes pedem medidas disruptivas - é isso que, atualmente, se perspetiva no domínio da e-Saúde. Cabe, no entanto, em períodos conturbados, analisar criticamente as soluções institucionais encontradas, para que nenhuma das finalidades pretendidas possa sair comprometida ou obliterada. 


\section{REFERÊNCIAS BIBLIOGRÁFICAS}

Centro Europeu de Prevenção e Controlo das Doenças - ECDC (2020). Technical Report-Mobile applications in support of contact tracing for COVID-19. A guidance for EU/EEA Member States. (junho de 2020). Disponível em https:/www.ecdc.europa.eu/sites/default/files/documents/COVID-19-mobile-applicationscontact-tracing.pdf.

Comissão Europeia (2015). Comunicação ao Parlamento Europeu, ao Conselho, ao Comité Económico e Social Europeu e ao Comité das Regiões - Estratégia para o Mercado Único Digital na Europa. COM(2015) 192 final. Bruxelas: 6 de maio de 2015.

Comissão Europeia (2017). Comunicação ao Parlamento Europeu, ao Conselho, ao Comité Económico e Social Europeu e ao Comité das Regiões sobre a revisão intercalar relativa à aplicação da Estratégia para o Mercado Único Digital - Um Mercado Único Digital conectado para todos. COM(2017) 228 final. Bruxelas: 10 de maio de 2017.

Comissão Europeia (2018). Comunicação ao Parlamento Europeu, ao Conselho, ao Comité Económico e Social Europeu e ao Comité das Regiôes sobre a viabilização da transformação digital dos serviços de saúde e de prestação de cuidados no Mercado Único Digital, a capacitação dos cidadãos e a construção de uma sociedade mais saudável. COM(2018) 233 final. Bruxelas: 25 de abril de 2018.

Comissão Europeia (2019). Research and innovation in the field of ICT for health, wellbeing and ageing: an overview. Bruxelas: Directorate-General for Communications Networks, Content and Technology - Digital Society, Trust and Cybersecurity. Disponível em https://ec.europa.eu/information society/newsroom/image/document/2019-33/health_ageing_projects_list_2019_6BC92EFF-90F3-8A94-09FBFA3C4DFD150E_61321.pdf.

Comissão Europeia (2020). Comunicação - Orientações respeitantes a aplicaçôes móveis de apoio à luta contra a pandemia de COVID-19 na perspetiva da proteção de dados. Bruxelas: 17 de abril de 2020. (2020/C 124 I/01).

Comissão Europeia (2020). Shaping Europe's Digital Future. Bruxelas: Publications Office of the European Union (fevereiro de 2020).

Comissão Nacional de Proteção de Dados - CNPD (2020). Deliberação no 2020/277, de 29 de junho de 2020. Processo PRE/2020/6.

Covelo de Abreu, J. (2019). O Mercado Único Digital e a interoperabilidade administrativa: a proteção de dados pessoais na articulação entre administraçôes públicas nacionais e as instituições e órgãos da União Europeia - reflexões prospectivas. In Amado Gomes, C., Neves, A. F., Bitencourt Neto, F. e Motta, F. (Coords.). O Direito Administrativo nos 30 anos da Constituição Brasileira de 1988 - Um diálogo luso-brasileiro. (pp. 206242). Lisboa: ICJP / CIDP. Disponível em https://www.icjp.pt/sites/default/files/publicacoes/files/ebook da30anoscb icjp15mar2019.pdf. 
Covelo de Abreu, J. (2019). Os serviços digitais na União Europeia: a interoperabilidade administrativa e a e-Saúde (eHealth), in Carvalho, M. M., E.Tec Yearbook - Health and Technology (pp. 53-68). Braga: JusGov Research Centre for Justice and Governance, School of Law - University of Minho. Disponível em https:// issuu.com/comunicadireito/docs/etec_yearbook_n2.

eHealth Network (2020). Mobile Applications to support contact tracing in the EU's fight against COVID-19 - Common EU Toolbox for Member States. Bruxelas. (Versão 1.0, 15 de abril de 2020). Disponível em https:// ec.europa.eu/health/sites/health/files/ehealth/docs/COVID-19_apps_en.pdf.

Fonseca, I. C. M. (2012). Direito da Organização Administrativa - Roteiro Prático. Coimbra: Almedina. pp. 21-23.

Freitas do Amaral, D. (2015), Curso de Direito Administrativo (Vol. I, 4a Edição). Coimbra: Almedina. pp. 87-114. 